\title{
A CRIANÇA COMO OUTRORIDADE: JOGO FICCIONAL E POÉTICA DA TEMPORALIDADE EM ALFREDO GARCIA E ONDJAKI
}

\author{
EL NIÑO COMO OTRORIDAD: JUEGO \\ FICCIONAL Y POÉTICA DE \\ LA TEMPORALIDAD EN \\ ALFREDO GARCIA Y ONDJAKI
}

Tânia Sarmento Pantoja ${ }^{1}$

\section{RESUMO}

O estudo apresenta a análise das narrativas "Quixote" (conto) e Bom dia, camaradas (romance), respectivamente de Alfredo Garcia e Ondjaki, com vistas a estabelecer algumas diretrizes encontradas em narrativas que reúnem um protagonista-narrador cuja perspectiva é a do indivíduo na infância, em associação com processos recordativos que implicam o jogo entre história e ficção, relacionado às figurações da violência de estado.

PALAVRAS-CHAVE: Narrativa; Infância; Memória; História; Alfredo Garcia; Ondjaki.

\section{RESUMEN}

El estudio presenta el análisis de las narrativas "Quixote" y Bom dia, camaradas (novela), respectivamente de Alfredo García y Ondjaki, con miras a establecer algunas directrices encontradas en narrativas que reúnen a un narrador niño, en asociación con procesos recordatorios y el juego entre historia y ficción, relacionado a las figuras de la violencia de estado.

PALABRAS CLAVE: Narrativa. Infancia; Memoria; Historia; Alfredo Garcia; Ondjaki. 


\section{INTRODUÇÃO}

Entre as décadas de 60 e 70, a terceira geração da escola dos Annales promove uma verdadeira desconstrução da história: considerando a subtração de recortes do real, a nova história não seria mais a História, mas histórias. Não mais a síntese das dimensões da realidade, mas a conquista de suas fraturas. Em ordem crescente e ao mesmo tempo decrescente, a história emergiria do "porão ao sótão" de maneira que tópicos até então negligenciados passam a ter seu lugar - a infância, a morte, a loucura, o clima, os odores, a sujeira, o corpo, a feminilidade, a leitura.

Nessa virada epistemológica, a literatura não ficou apática a essas diretrizes e nesse sentido têm-se observado narrativas ficcionais assentadas sobre processos que constituem e problematizam dicotomias como história/ficção, particular/geral ou presente/passado, numa confrontação por si só contraditória, na medida em que coloca o consenso entre as partes como uma ilusão, ao mesmo tempo em que aflora à escrita vozes até então invisibilizadas ou obscurecidas.

Nesse périplo, essa produção literária tem se encontrado ainda com o dever de memória, nascido da era das Catástrofes e dos Testemunhos. Deve assim haver lugar para os reajustes narrativos da recordação, o que implica examinar os elementos agônicos presentes na ordem constitutiva dos processos imersos nas tantas matérias historiográficas de que essa produção se alimenta. Processos que se tornam ainda mais proeminentes quando atravessados pelas condições de expressão da violência, do trauma, mas, ao mesmo tempo, da resistência ou mesmo do ressentimento. Esses estatutos no campo da expressão artística indicam a todo o momento o quanto é imprescindível lembrar que narrar é conhecer.

Narrar é também dar a conhecer. Parte daí uma das principais preocupações de Beatriz Sarlo (2007). Ao refletir acerca das dimensões do testemunho, Sarlo não esquece em nenhum momento que testemunhar, antes de tudo, é narrar. Por isso é necessária a especulação infinita sobre essa relação, tanto da parte de quem produz a narrativa, quanto da parte de quem dela faz a recepção, pois memória e história nem sempre são coetâneas e nem sempre coincidem na urdidura da narrativa: "nem sempre a história consegue acreditar na memória, e a memória desconfia de uma reconstituição que não coloque em seu centro os direitos da lembrança (direitos de vida, de justiça, de subjetividade)" (SARLO, 2007, p. 9).

Para Sarlo, ressalta-se, é necessário racionalizar o discurso memorialístico a fim de fazê-lo expressar as engrenagens que o constituíram como artefato, produzido a partir de um lugar de enunciação, tornando-o capaz de se revelar como expressão individual e como instrumento político. Nos passos de Sarlo, cito Luiz Ruffato, que no prefácio para a edição brasileira do romance Bom Dia Camaradas, de Ondjaki, afirma: "não é o que se conta o que importa, mas como se conta” (RUFFATO, 2006, p.12). 
Em face da apropriação da memória pelo texto literário, certamente pode haver perdas em relação às correspondências entre memória e história, mas as possibilidades do laboratório criativo são múltiplas e intensas. A literatura cria muitas formas de problematizar as suspeitas que Beatriz Sarlo levanta em relação à memória, não porque tome para si a memória atravessada por um dever de verdade, muito pelo contrário, mas talvez porque seu compromisso seja enfim especular sobre por que lembramos e para que lembramos. Nesse sentido, se todo narrador do testemunho é sempre assaltado pela necessidade de estabelecer correspondências mínimas com a história, a literatura oblitera essa necessidade, muitas vezes concedendo protagonismo a narradores profundamente não confiáveis, que mesmo assim não se esquivam de narrar suas memórias. Um dessas formas de protagonismo é a da criança ou a do adolescente.

Desse modo, considerando a dimensão do contar e o território de onde se conta, pretendo neste estudo construir a reflexão sobre como a criança, enquanto narradora, pode constituir-se em importante medium de organização narrativa, na medida em que a experiência da narração se mistura a processos memorialísticos, comprometidos com a reelaboração de determinados cenários históricos, em particular aqueles imersos em regimes autoritários. A questão que mais efetivamente acompanha a análise das narrativas é a seguinte: o protagonista-narrador, na condição de criança, funda uma alteridade que hiperboliza outras alteridades e por isso apresenta a possibilidade de desencriptar aspectos que tendem a ficar esquecidos, justamente por se constituírem de representações da violência. Narrativas com essas condições ainda tendem a apresentar um horizonte de desenvolvimento da resistência, baseada na ideia de que a criança pode representar a possibilidade de uma transformação positiva. Para além dessas caracterizações é uma literatura que dá protagonismo à infância, uma dentre as muitas vozes que permaneceram ao largo das histórias oficiais por muito tempo.

Essas narrativas apresentam como primeiro ponto em comum o que chamo justamente de protagonismo infantil. Nos limites do presente estudo, consistem, respectivamente, no conto "Quixote", pertencente à coletânea Aqueles meninos que fomos (2007), do brasileiro Alfredo Garcia, e o romance Bom Dia Camaradas (2001), do angolano Ondjaki. Um segundo ponto em comum é o fato de que ambas partem de uma matéria historiográfica, digamos, consumada. A narrativa de Ondjaki localiza-se em uma Angola do final da década de 1980, após a guerra colonial, mas ainda no contexto da Guerra Fria e ainda imersa em formas de controle da população que são remanescentes do contexto de ambas as condições anteriores. Por sua vez, o conto "Quixote" tem como pano de fundo histórico a guerrilha do Araguaia, importante episódio desenvolvido no interior da ditadura civil-militar de 1964. 


\section{O PROTAGONISMO INFANTIL EM “QUIXOTE" E BOM DIA, CAMARADAS}

Giorgio Agamben, ao pensar sobre as relações entre brincadeira e infância, propõe uma categoria capaz de fortalecer o trabalho com as correspondências: a miniaturização, essa capacidade de ver um recorte de algo em uma escala menor, substancialmente como uma maquete e, portanto, como um objeto reduzido, mas, por isso mesmo, com possibilidade de ser observado de uma perspectiva mais ampla. Uma brincadeira funciona como miniatura, um recorte pontual da experiência com base na performatização dos objetos, dos papeis e das situações, permitindo ao observador a possibilidade de olhar de muitas perspectivas e até mesmo interagir remodelando o cenário. Por essa capacidade performatizadora, a miniatura, enquanto processo, acessa correspondências com a vida, alcançando a temporalidade que desse modo impregna o brinquedo.

Há um corpus de narrativas literárias e cinematográficas em que facilmente se percebe a associação entre protagonismo infantil e matérias históricas relacionadas à violência de Estado nos séculos XX e XXI. A título de exemplo, cito as produções espanholas O labirinto do Fauno, a francesa A culpa é do Fidel, a salvadorenha Vozes inocentes, a argentina Kamchatka e as chilenas Postales de Leningrado e Machuca. São películas que envolvem temas ligados aos regimes totalitários e autoritários nesses dois séculos, como as ditaduras de Franco e aquelas desenvolvidas na América Latina. Além das implicações da matéria histórica, é importante salientar que o trabalho de rememoração é um aspecto problematizador a marcar narrativas com esse tipo de abordagem e perspectiva narrativa.

Como jovem testemunha, a criança - ou o adolescente - rememora segundo diretrizes muito peculiares. O testemunho por si só é elíptico, mas se o testemunho é de uma criança essa condição se mostra ainda mais potencializada: o olhar da criança é um olhar míope e infinitamente transitivo. Nesse sentido, o trabalho recordativo que envolve o tempo da infância precisa lidar com o preenchimento de vácuos, mas não se presta apenas a uma operação de substituição das partes "perdidas" e preenchidas pela economia da imaginação. Trata-se, sobretudo, de dar significação a uma situação muito singular da experiência. É nesse processo que a narrativa se torna um modo substancial de indagação, não somente em relação à história, mas, sobretudo em relação à experiência vivida.

Nas duas narrativas aqui analisadas o protagonista, ex-menino, rememora a partir de um tempo que é um "tempo de agora", tempo do adulto que volta o olhar - e por conseguinte o ato rememorativo - para o tempo da infância, também um tempo de infâmias por se revelar uma temporalidade marcada pelo conflito. Esse olhar lançado ao passado é o olhar do póstero que um dia foi criança e, portanto, é lugar da nostalgia, mas é o olhar também da reinvenção que abraça o passado, performatizando-o e ressignificando-o. Nesse percurso, digo que a narrativa é autoconsciente 
nessa relação com o tempo pretérito: a criança que um dia foi esse adulto de agora é já uma outridade não dissociada de uma outroridade: em outras palavras, a autoconsciência de ser outro em um mesmo sem perder de vista a separação entre duas ou mais temporalidades, sendo uma delas um tempo de outrora.

\section{"QUIXOTE": NARRATIVA DE UM (IM)POSSÍVEL CHÃO}

No conto "Quixote" temos o protagonismo do personagem Antônio Guimarães, na infância também conhecido por Toinho, que na condição de adulto narra, com base em reminiscências, importantes experiências vividas na infância. O conto "Quixote" é uma narrativa pós-ditatorial com protagonismo infantil, como várias outras que seguem esse mesmo paradigma, como as películas anteriormente citadas e ainda as narrativas literárias Carapintada, do brasileiro Renato Tapajós; O ruído das coisas ao cair, do colombiano Juan Gabriel Vásquez; Se vivêssemos em um lugar normal, do mexicano Juan Pablo Villalobos.

A narrativa resulta do entrelace entre duas perspectivas oriundas de um mesmo narrador: a do adulto no presente e a da criança no passado recente. Com nuances do testemunho, o relato agrega importante matéria histórica relacionada a episódio bastante conhecido no interior da Ditadura Militar de 1964: a Guerrilha do Araguaia, guerrilha rural deflagrada próximo às margens do rio Araguaia, numa região conhecida como Bico do Papagaio, localizada na fronteira entre os estados do Pará e Goiás, ao norte do Brasil. Após a instauração do AI-5, o braço armado do regime inicia uma agressiva campanha contra as guerrilhas. Por sua vez, as estratégias desenvolvidas pela guerrilha rural, especialmente em seus momentos iniciais, incluíam aproximar-se dos nativos e fazer o reconhecimento do território. É com esse cenário geopolítico que esse conto de Garcia vem dialogar.

A narrativa não oferece indicações sobre a idade exata de Antonio quando envolvido com as situações narradas, mas ele parece ser ainda bem menino no tempo recordado e esse tempo recordado ganha estatuto narrativo de um "tempo remoto" (GARCIA, 2007, p. 53). Nesse processo, o trabalho recordativo tem importante repercussão na constituição da narrativa, uma vez ser o conto resultante de um conjunto fragmentário de reminiscências e referências entrecruzadas, nem sempre claras para o narrador:

Tínhamos vindo parar naquele lugarejo logo depois que a mãe desapareceu num ano que eu não lembro quando, mas recordo ter sido no mês de abril. Um irmão dela era dono da venda no lugar, o pai tinha perdido o emprego sei lá porque. Deixara de ir ao escritório da repartição, e era só o que eu sabia. Um dia reunimos todas as coisas ele enterrou uns livros dentro de caixas de metal numa cova funda no quintal, e saímos da cidade. (GARCIA, 2007, p. 48) 
O acesso do narrador aos indícios históricos é limitado, porém suficiente para a constituição de inferências pelo leitor. Esses indícios estão espalhados pela narrativa, mas em uma sequência controlada, como rastros organizados. Por exemplo, o desaparecimento inexplicável da mãe em um certo "abril" são reveladores da relação com uma das principais estratégias utilizadas pelo regime: as desaparições. Essa indicação e mais a evidente associação com a resistência armada no Araguaia intensifica-se diante da conotação histórica: é em um mês de abril, mais propriamente em 12 de abril de 1972, que ocorre o primeiro confronto entre os guerrilheiros instalados na região mencionada e as Forças Armadas.

Outra referência são os livros enterrados no quintal. Livros de um pai professor desempregado por motivos não esclarecidos. Ora, livros só precisam ser ocultados no contexto da sedição ou das ideias contestatórias, tão próprias às resistências construídas no interior do funcionamento dos governos autoritários. O policiamento da produção e circulação do conhecimento e, por conseguinte a censura aos livros fazem parte dos dispositivos que movimentam a máquina repressiva da governabilidade em tempos de repressão. A necessidade de ocultar os livros, seguida de uma retirada às pressas para um lugarejo distante, para tomar conta de uma venda pertencente ao irmão da esposa desaparecida, insinua que não apenas o pai estaria envolvido em ações subversivas, mas que poderia ser incriminado por defender ideias clandestinas, contidas nesses livros proibidos, de modo que além de ocultar seus livros ele mesmo necessita tornar-se clandestino. Nesse sentido, vale ressaltar a existência de estudos atualmente disponíveis (MORAES \& SILVA, 2005 e NOSSA, 2012) a indicar o papel das "vendas" como importante na infiltração da guerrilha entre os moradores locais. De modo que, diante dessa verdadeira teia de aparentes perdas e manobras de esquiva para sobreviver, não custa supor que toda a família do menino tenha aderido à instalação da guerrilha.

Referências intertextuais ligadas ao campo literário, igualmente integradas às recordações do narrador, reforçam essa possibilidade de leitura, na medida em que o conjunto de referências forjam um estatuto utópico - de resistência - que será o fio de Ariadne da jornada dos dois heróis, pai e filho, em busca de ao mesmo tempo resistir e sobreviver. As referências literárias estão bem encaixadas nesse argumento, pois forjam o paralelo que o garoto faz entre o pai, os parceiros do pai recém-chegados ao território da sobrevivência e os personagens de Miguel de Cervantes Dom Quixote e o escudeiro Sancho Pança, que se tornam codinomes dos dois desconhecidos que surgem em visita ao pai do menino.

A deferência ao texto cervantino, que já habita o título do conto, é preciosa e fundamental para a ressignificação da temporalidade rememorada: Geraldo Witeze Jr. mostra como na década de 70 do século XX a recepção crítica por parte de estudiosos do texto de Cervantes - a exemplo de C. Blanco Aguinaga, por ele citado - encontra no Quixote uma: 
"mente organizada de modo humanista e inclusive científica", que luta "contra os conceitos tradicionais de limpeza de sangue" e diferença entre linhagens" e defende "a igualdade e a dignidade dos seres humanos"'. Assim, Dom Quixote mostra a realidade contraditória de sua época" (WITEZE JR, 2011, p. 214).

Witeze Jr refere ainda outro estudioso do Quixote, Edward Riley, que também na década de 70 lê o engenhoso fidalgo na chave das relações entre história e ficção. No percurso dessas leituras, conforme compreende Witeze Jr, Cervantes:

estabelece diferença entre as duas, sabe que na ficção a verdade poética prevalece, mas também que esta depende em parte da verdade histórica. Mesmo escrevendo com rigor de historiador, Cervantes tinha um gosto pelo maravilhoso e em sua prosa tratou de reconciliá-lo com a vida (WITEZE JR, 2011, p. 215).

Considerando essa recepção crítica Alfredo Garcia parece movimentar as heranças de Cervantes em dupla operação de pastiche: quanto ao procedimento e quanto ao argumento, pois a dimensão confrontadora da realidade, presente no texto do Quixote, se dá exatamente nesse diálogo muito elegante com os referentes históricos, que o conto reivindica para si ao modo metarreflexivo, ao mesmo tempo em que potencializa a luta dos guerrilheiros no interior de uma dimensão utópica, perceptível na finalização da narrativa do conto:

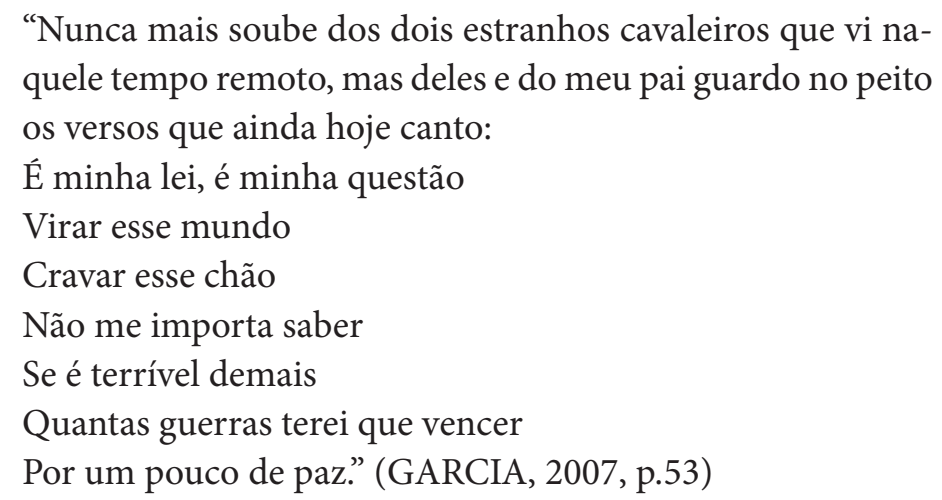

Outra referência a merecer destaque é justamente a canção "Sonho impossível", que se encontra agregada à narrativa do conto, cuja letra de clara inspiração drummondiana menciona a importância de resistir, independente de quantas guerras precisem ser vencidas, para que uma flor possa "brotar do impossível chão". Essa teia de relações intertextuais marca a memória do narrador e alicerça uma ética para a resistência como forma de vida, que parece repercutir e permear o presente de sua existência.

São, portanto, as recordações de um tempo recente e presente, presente, especialmente por se fazer contemporâneo, constituídas ao ritmo do testemunho, com a cumplicidade do referente histórico, que estabelecem no menino do presente (agora já adulto), um distanciamento nostálgico a partir de uma mirada que evidencia, sobretudo, o aprendizado para a resistência. 


\section{BOM DIA, CAMARADAS: A FALA COMO ECLOSÃO DE COISAS NOVAS}

Como já observado por Henrique Evaldo Jansen (2011) Bom dia, camaradas é uma narrativa assumidamente "de fundo autobiográfico" e, da mesma forma que no conto analisado anteriormente, adota o paradigma da memória póstera "recorrendo a um autor-narrador adulto que percebe o mundo pelo olhar infantil"; nesse sentido tem-se um texto que funciona como trabalho recordativo ao mesclar as lembranças de um menino e sua vida em família com a filtragem de situações vinculadas ao contexto da guerra civil angolana. Como evidencia Joseana Stringini da Rosa:

"Com uma visão infantil e de classe média, o menino narra os pequenos acontecimentos do seu cotidiano. O livro é repleto de histórias aparentemente comuns, como as festinhas e os lanches na casa de colegas, os passeios e a visita da tia, vinda de Portugal, e certos acontecimentos do ambiente escolar" (ROSA, 2012, p. 69).

O esforço em concentrar a focalização desse menino no pretérito ao invés de fazê-la no adulto do presente é uma estratégia ficcional que nas palavras de Karina Vieira torna complexa a relação entre o romance e a narrativa de si, uma vez que nas formas clássicas autobiográficas a focalização tende a vincular-se ao narrador do presente:

Em Bom dia, camaradas, ocorre justamente o contrário: a focalização narrativa é mantida sobre o personagem, o menino que vive os acontecimentos, o eu passado de Ondjaki, no plano autobiográfico. O menino/personagem é, simultaneamente, sujeito da história e do discurso, pois vive os fatos e relata-os, em uma linguagem marcadamente infantil. (VIEIRA, 2010, p. 10)

Para além dessa constituição do narrador, o romance de Ondjaki também é subversivo na medida em que esse mesmo narrador é inspirado na forma do griot (BAYER, 2008, p.1), tão própria da narrativa oral, para compor um rico painel fundado nas relações entre relatos distintos e que têm - no caso do romance em tela - a memória sensorial, especialmente a memória olfativa (BAYER, 2008, p.3), como uma das principais constituintes da performance desse narrador.

Por constituir-se como produto da filtragem de dados recordados no decorrer do processo rememorativo, tal como em "Quixote", também em Bom dia, camaradas o acesso do narrador aos indícios históricos são limitados, ora envolvidos pela graça e fluidez do tom anedótico, ora assumidamente resultante da reelaboração do testemunho de um primeiro. De qualquer forma, é uma narrativa fundada na concepção de que a criança funciona como um ruído que atua como diferença, tanto pelo uso marcante de expressões capazes de atestá-la como uma perturbação: "esse menino!" ou "esse menino é terrível", quanto pela possibilidade de conceber a criança como alegoria de um país em reconstrução. 
Nesse percurso, ressalta-se certa arqueologia presente para dar compreensibilidade às dinâmicas de um país que vê na necessária disciplina e organização as diretrizes para que a reconstrução se faça, mas essa talvez seja apenas a outra face de uma existência marcada pela anomia. Diretrizes atuantes no cotidiano das crianças ao ponto de tornar a vida surpreendentemente previsível - e assustadora. Essa adesão repercute efeitos na medida em que o filho, esse menino/narrador, advinha toda a rotina da mãe, bem como apreende valores e nesse percurso a convivência em família pode tranquilamente funcionar como uma miniatura da convivência coletiva da nação e, nesse sentido, é parte do processo formativo das crianças.

Nesse contexto, vale a pena ressaltar a presença dos professores cubanos no interior de um conjunto de situações que, por um lado, significam o contato muito próximo com um paradigma da resistência que de certa forma é questionado e, por outro lado, registram o encontro de alteridades, plenamente apreensíveis para as crianças - línguas diferentes; variadas formas da língua materna; diferentes formas de pensar a reconstrução do lugar onde vivem, mas esses contatos estão longe de serem tranquilos: a criança sempre lança a essas situações um olhar perscrutador e desconfiado, de quem se espanta, confere e por vezes até dissimula. Esse percurso é ainda marcado pelas reminiscências do heroísmo revolucionário latino-americano, que sofre estranhamento até tornar-se anedota risível, ao mesmo tempo em que fortalece o espaço do pioneiro honrado, representado pela figura de Ngangula, o adolescente que, reza o mito, mesmo sob forte tortura não delatou os companheiros do MPLA.

Cabe salientar ainda que o cenário de Bom dia, camaradas é uma jovem Angola, recém-liberta do poder colonial, mas ainda envolta em movimentos estruturantes, com espaço para a violência oriunda de conflitos internos: há a guerra civil entre o governo de Agostinho Neto e as forças da UNITA e FNLA. Ao mesmo tempo em que é espaço de fortes dissidências políticas, Angola vive a experiência da economia planejada de bandeira socialista (VIEIRA, 2010, p. 3). É nesse cenário que nasce e vive o menino Ondjaki.

Os indícios históricos sem dúvida penetram e permeiam o tecido ficcional: aspectos da vida social e econômica do país repercutem na rotina da criança, como no episódio da chegada da personagem Dada, tia do protagonista, ao mostrar desconhecer as minúcias referentes aos mecanismos de controle do governo:

\footnotetext{
- Não posso tirar uma fotografia àquele macacaquinho tão inofensivo?

- Não, tia, não podes...

- E porquê?

- Não sei se vais perceber...

- Então diz lá. Diz ela séria.

- Não podes tirar fotografias àquele macaco..., por razões de segurança de Estado, tia - eu, sério. (ONDJAKI, 2006, p.60)
} 
Por sua vez, o convívio permanente com as diferentes faces da disciplina estatal e da violência derivante do conflito político leva as personagens a cotejarem a reorganização do espanto, do medo e do estranhamento diante de situações não experimentadas, da necessidade de fugir diante dos perigos que cercam sua rotina, já demasiado invadida e ocupada com as "razões de estado". Nesse sentido, se as "razões de estado" precisam ser seguidas à risca, pois o risco é sempre imprevisível, as razões do medo infiltram-se pela infância à sombra da possibilidade de violação, como na história sobre o Caixão Vazio, e deslizam, ao modo de uma brincadeira, para táticas de preservação e sobrevivência em formato de miniatura:

Também ninguém se interessou pela discussão, porque estávamos todos mais preocupados com a questão do Caixão Vazio, se eles iam ou não aparecer na nossa escola. O Murtala apostava que sim, porque eles tinham estado a semana passada numa escola ao pé do mercado Ajuda-Marido, que já era bem perto da nossa. O Murtala desenhou na areia um mapa bem fixe, com o Largo das Heroínas, o mercado, o Kiluanji, o Kanini e a nossa escola. Foi bom ele ter feito esse mapa e explicar-nos o que ele pensava que ia acontecer, porque mesmo ao lado o Claudio desenhou um mapa da nossa escola e cada um disse logo ali quais eram as melhores hipóteses de fuga, contando com o peso da mochila ou não, com o facto de eles nos perseguirem ou não e até a possibilidade de os camaradas professores cubanos - com essas histórias da rvolução - quererem fazer trincheira e desafiar o Caixão Vazio. (ONDJAKI, 2006, p. 44)

Esse quadro recordativo intenso não deixa escapar ainda as reminiscências do terror, como aquelas que são produto de lendas urbanas, a exemplo do já citado Caixão Vazio ou as anedotas sanguinárias, que não deixam de ser projeções abjetas da violência urbana a repercutir nas histórias que o menino narrador conta para tia Dada, com a naturalidade de quem conhece o que narra e assim consegue exorcizar o medo.

Essas relações instauradas colocam o menino protagonista na condição de um narrador que, sobretudo, além de testemunha é também um estranhador a tentar compreender as coisas e os afetos, especialmente quando o testemunho é sobre os sentimentos perante a morte e a deambulação diante da água como metáfora da transformação, aspecto que, como bem observa Joseana Stringini da Rosa, aborda "uma das marcas do povo angolano, presente no livro: a esperança de dias melhores". (ROSA, 2012, p. 68). De fato, o menino e sua memória - associada à palavra pensada, falada ou escrita - pode ter a mesma função da água da chuva ao final do romance: fazer "o chão dar folhas novas." (ONDJAKI, 2006, p. 237)

\section{CONSIDERAÇÕES FINAIS}

Frente às narrativas com protagonismo infantil, como "Quixote" e Bom dia, camaradas, sobretudo marcadas pelo traço adicional do referente historiográfico, destaca-se a configuração de um narrador, cuja matriz parece ser a narrativa de si, mas que dela se aproxima e se afasta em 
tom subversivo, como aquilo que difere e ao mesmo tempo complementa e, para além do truque narrativo, evoca o lugar de um outro que não sendo o "eu", pois é seu passado, ainda assim é (mais) uma pele que o veste: mais do que outridade é uma outroridade.

Essas dimensões constituintes da narrativa, por outro lado, realçam a relação entre ficção-história e passado-presente compostos nesse intervalo - traduzido como jogo ficcional em que a criança se assume como "pele" aprendiz que proporcionará um adulto (talvez) mais disposto à transformação no horizonte, sobretudo, da autorrevolução. Desse modo, essa outroridade alimenta o presente de uma dimensão esperançosa, que acena ao texto como potência de vida.

São, dessa forma, narrativas avassaladoras e como tais, desviantes. Não apenas por essa "pele" que salta de um tempo pretérito para assegurar uma performance (ainda) passível de fazer despontar uma ética baseada em resistência, por sua vez fundada em compromisso. Sobretudo, pelo fato de que a criança representa um ruído. Sua visão limitada das coisas ao redor paradoxalmente é capaz de ampliar e desobliterar verdades ao derivar para o estranhamento que ultrapassa os tempos evocados, e desse modo é capaz de atualizar a necessária divergência, alimentada pela nostalgia de um Bom tempo que, mesmo correndo o risco de nunca ser, se faz de alguma forma presente.

\section{REFERÊNCIAS BIBLIOGRÁFICAS}

AGAMBEN, Giorgio. História e Infância: destruição da experiência e origem da história. Tradução de Henrique Burigo. Belo Horizonte: UFMG, 2005.

BAYER, Adriana Elisabete. O percurso do menino-griot: das despedidas à aprendizagem1. Nau Literária . Porto Alegre - Vol. 04 N. 01 - jan/ jun 2008. Disponível em http://www.seer.ufrgs.br/index.php/NauLiteraria/ article/view/5803/3408.

GARCIA, Alfredo. Quixote In: Aqueles meninos que fomos. Ananindeua: Populivros, 2007.

JANSEN, Henrique Evaldo. Bom dia Camaradas - resenha. Educ. Rev. n. 39, Curitiba, Jan/Apr., 2011

ONDJAKI. Bom dia camaradas. Rio de Janeiro: Agir, 2006.

ROSA, Joseana Stringini da. Entre a ficção e a realidade: Bom dia camaradas e a esperança de dias melhores através do olhar infantil. Ao pé da Letra, V. 14.2 - 2012. Disponível em http://www.revistaaopedaletra.net/ volumes-aopedaletra/Volume\%2014.2/Volume14-2_Joseana-Stringini-da-Rosa.pdf

RUFFATO, Luiz. Bom dia, camarada leitor brasileiro. In: ONDJAKI. Bom dia camaradas. Rio de Janeiro: Agir, 2006, p. 9-13. 
SARLO, Beatriz. Tempo passado: cultura da memória e guinada subjetiva. Tradução Rosa Freire d’Aguiar. São Paulo: Companhia das Letras/ Belo Horizonte: UFMG, 2007

VIEIRA, Karina Mayara Leite. Pelos caminhos da memória: a Angola do pós-independência revisitada por Ondjaki. África e Africanidades, Ano 3, n. 10, ago., 2010. Disponível em http://www.africaeafricanidades.com. br/documentos/10082010_10.pdf.

WITEZE JÚNIOR, Geraldo. Os muitos caminhos do Quixote: pluralidade de vozes e interpretação. Memento, V. 2, n. 2, ago.-dez. 2011 . Disponível em file:///C:/Users/eletro\%20magazan/Downloads/Dialnet-OsMuitosCaminhosDoQuixote-3873758.pdf

Recebido para publicação em 30/10/2017

Aprovado em 29/01/2018

\section{NOTAS}

1 Doutora em Estudos Literários pela Universidade Estadual Paulista Júlio de Mesquita Filho (UNESP/CAr). Professora de Literatura Portuguesa na Graduação em Letras-Português e do Programa de Pós-Graduação em Letras, da Universidade Federal do Pará. 